\title{
转座子 $\operatorname{Tn} 233(\mathrm{CH})$ 的物理图
}

\author{
洪孟民王宗阳陈剑民张景六蔡瑞珠杨蕴刘郑霏琴 \\ （中国科学院上海植物生理研究所）
}

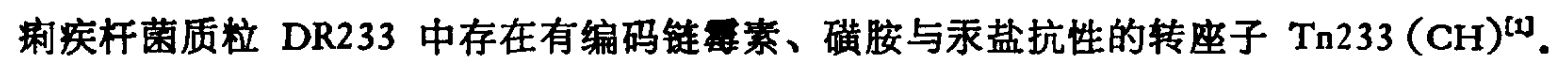
为了研究它的分子特性, $\mathrm{Tn} 233(\mathrm{CH})$ 被转座到质粒 $\mathrm{pBR} 322$ 上, 组建成质粒 $\mathrm{pBR} 322:: \mathrm{Tn}$ $233(\mathrm{CH})^{[2]}$. 图 1 为 $\mathrm{pBR} 322:: \mathrm{Tn} 233(\mathrm{CH})$ 与 $\mathrm{pBR} 322 \mathrm{DNA}$ 的电镜照片. $\operatorname{Tn} 233(\mathrm{CH})$ 的 限制性内切酶 EcoRI、BamHI、HindIII、PstI、PvuII、SalI 与 BglII 的物理图按下法建成.

1. EcoRI 与 BamHI 切点的国质粒 pBR322::Tn233(CH) DNA 分别经 EcoRI、 BamHI 单酶消化或 BamHI-EcoRI 双酶消化。经消化后的 DNA 在 $1.0 \%$ 的琼脂糖凝与 $5 \%$ 的聚丙烯酰胺胶上进行电泳(图 2). 消化后分别形成的 E、B 与 BE 片段的分子大小见表 1 . 因为 $\mathrm{E} 3 、 \mathrm{E} 4 、 \mathrm{E} 5 、 \mathrm{E} 7 、 \mathrm{E} 8$ 与 $\mathrm{E} 9$ 片段的分子大小与 $\mathrm{BE} 1 、 \mathrm{BE} 2 、 \mathrm{BE} 5 、 \mathrm{BE} 6 、 \mathrm{BE} 12$ 与 $\mathrm{BE} 13$ 的分子大小相同，因此在这些 $\mathrm{E}$ 片段中没有 BamHI 切点. 但是表 1 的数据指出 E1、E2、E6 与 $\mathrm{E} 10$ 片段必定含有一个或多个 BamHI 切点. 然后将 E1 到 E7 片段各个地从电泳后的 凝胶中洗脱下来,并用 BamHI 消化. 消化物的电泳分析说明除了 E3、E4、E5 与 E7 片段 外，E2 片段产生 BE3 与 BE11 片段; E6 产生 BE7 与 BE9 片段; E1 产生 BE4、BE8、 BE10 与 BE14 片段. 用相似的分析方法也说明 B3、B5 与 B6 片段中没有 EcoRI 切点, 而 B4 片段产生 BE5、BE8 与 BE15 片段; B1 产生 BE2、BE3 与 BE9 片段; B2 产生 BE1、 BE6、BE10、BE11、BE12 与 BE13 片段. 在每个 B 与 E片段中 BE 片段的次序可以根据它 们的连接关系按表 2 的形式列出. 并能进一步确定 $\mathrm{B}$ 与 $\mathrm{E}$ 片段的排列次序如下:

$$
\text { L6-E4-E2-(E8, E9, E3, E7)-E1-E5-E10 与 } \mathrm{L}^{\mathrm{B} 5-\mathrm{B} 1-\mathrm{B} 2-(\mathrm{B} 3, \mathrm{~B} 6)-\mathrm{B} 4} \text {. }
$$

2. HindIII 与 PstI切点的储图图 3 与表 1 为 pBR322 :: Tn233 (CH)DNA 经 Bam HI、HindIII 或这两种海的混合消化并经电泳后所得到的限制类型. 根据这些分析结果与相 同的道理，H片段的排列次序为: $\mathrm{H} 1-(\mathrm{H} 2, \mathrm{H} 6)-\mathrm{H} 3-\mathrm{H} 7-\mathrm{H} 4-\mathrm{H} 5$ (表 3). 这些结果还表明片

段 B3 是与 B2 相连接,因此 B 片段的次序为: B5-B1-B2-B3-B6-B4.

pBR 322 :: Tn233 (CH) DNA 经 PstI 消化后产生两个片段 Ps1 与 Ps2. 用 BamHI 与 EcoRI 切点的图位作为参考, 弄清此两个 PstI 切点位于 B2, B3 或 E1, E3 片段内 (图 4). PstI 切点在图上位置的确定有利于 E3、E7、H2 与 $\mathrm{H} 6$ 片段的定位. 这样 $\mathrm{H}$ 与 E 片段的排 列为: $\mathrm{H} 1-\mathrm{H} 2-\mathrm{H} 6-\mathrm{H} 3-\mathrm{H} 7-\mathrm{H} 4-\mathrm{H} 5$ 与 $\mathrm{E} 6-\mathrm{E} 4-\mathrm{E} 2-\mathrm{E} 3-\mathrm{E} 7-(\mathrm{E} 9, \mathrm{E} 8)-\mathrm{E} 1-\mathrm{E} 5-\mathrm{E} 10$ j 其中 $\mathrm{E} 9$ 与 E8 的准确位置尚末测出.

\section{Prull、Sall 与 Bglll 切点的制国 将 $\mathrm{pBR} 322:: \operatorname{Tn} 233(\mathrm{CH})$ 的 EcoRI 限制类型}

本文 1981 年 12 月 23 日收到。 


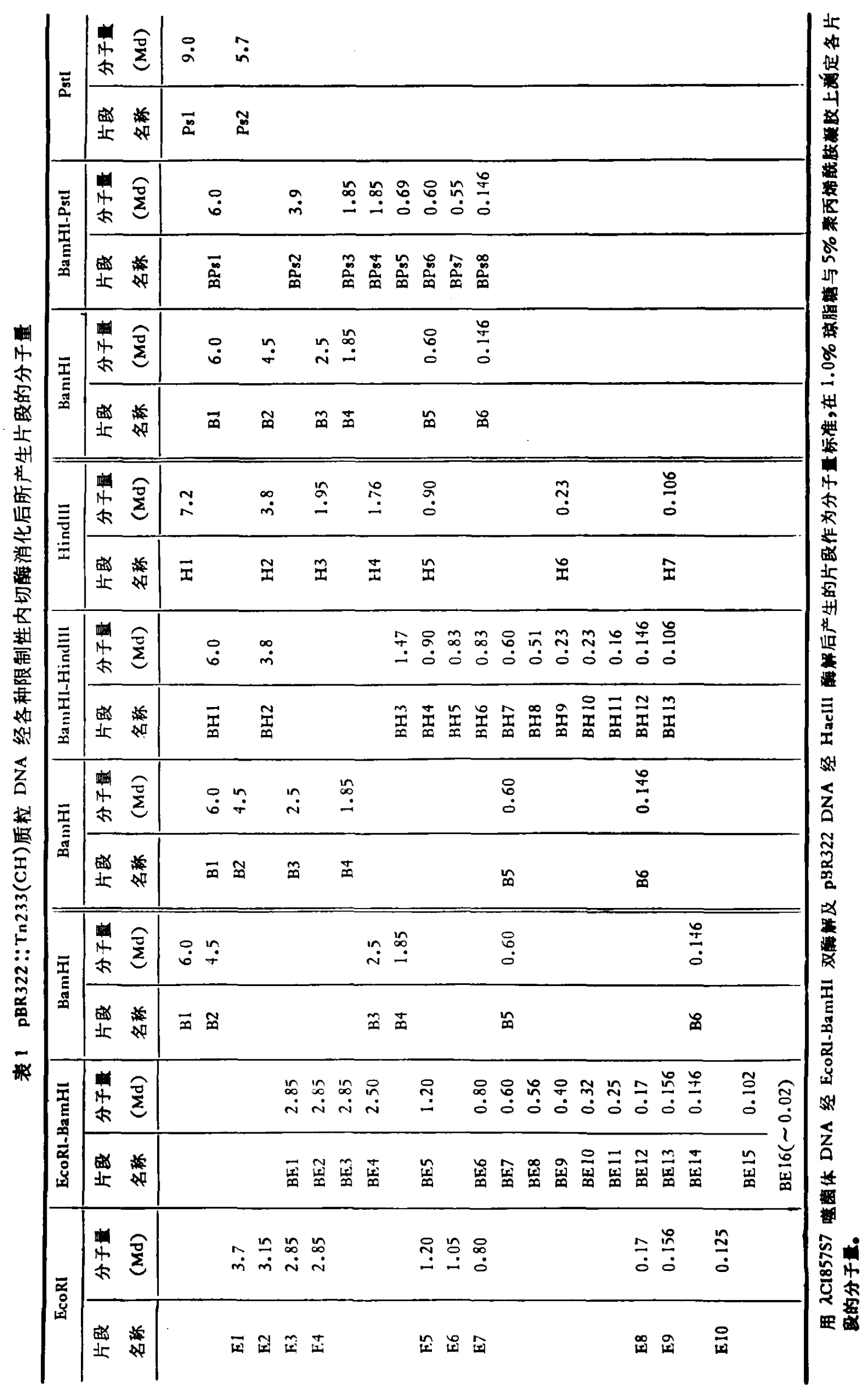




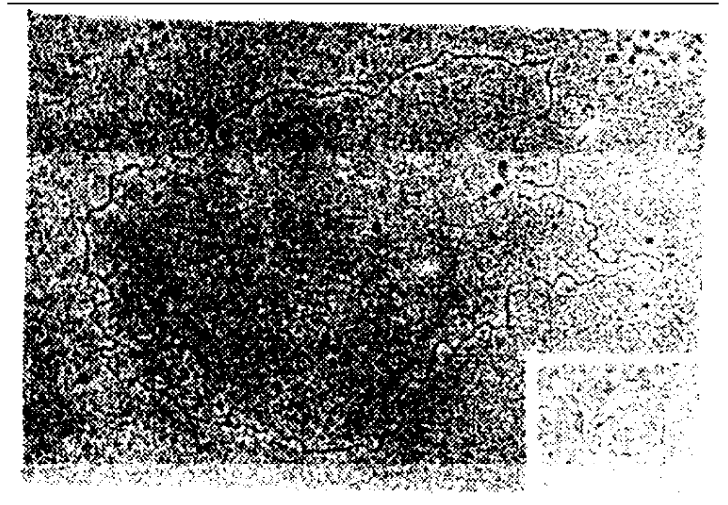

图 1 pBR322:: Tn233(CH) 质粒 DNA 的电镜照片

显示一个 pBR322:: Tn233(CH) 的开环分子, 小环为 pBR322 DNA，放大倍数 $\times 25000$

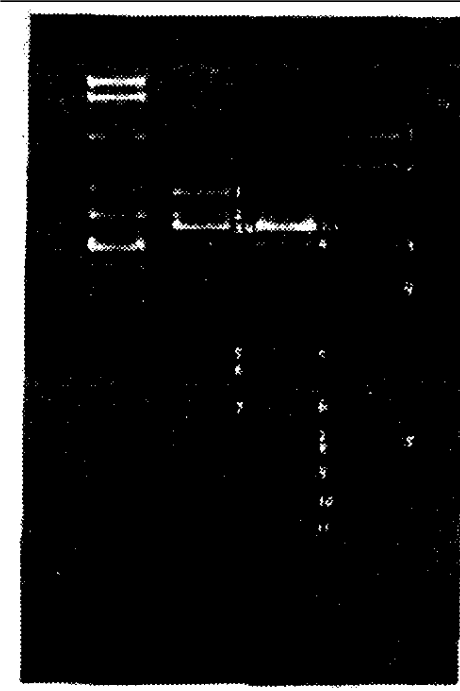

a b c c d

e f $\mathrm{g} \mathrm{h}$ i

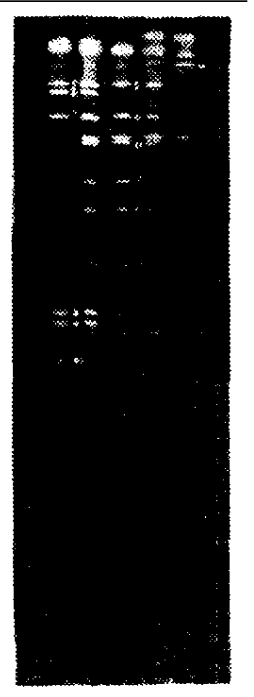

DNA 经限制生内切消化后的产物

DNA 经 EcoRI(b), BamHI-EcoRI(c),BamHI(d), EcoRI(e)、e + g(f)、BamHI-EcoRI (g)、g + i(h)、 BamHI(i)完全消化后, 在 $1.0 \%$ 琼脂精 $(a, b 、 c 、 d)$ 与 $5 \%$ 聚丙㛓酰胺 $(e, f, g, h, i)$ 胶上电永。经 BamHI-EcoRI 消化后的 $\lambda$ CI857S7DNA (a) 作为分 子年标准

表 2 各 E、B与 BE 片段间的相互关系

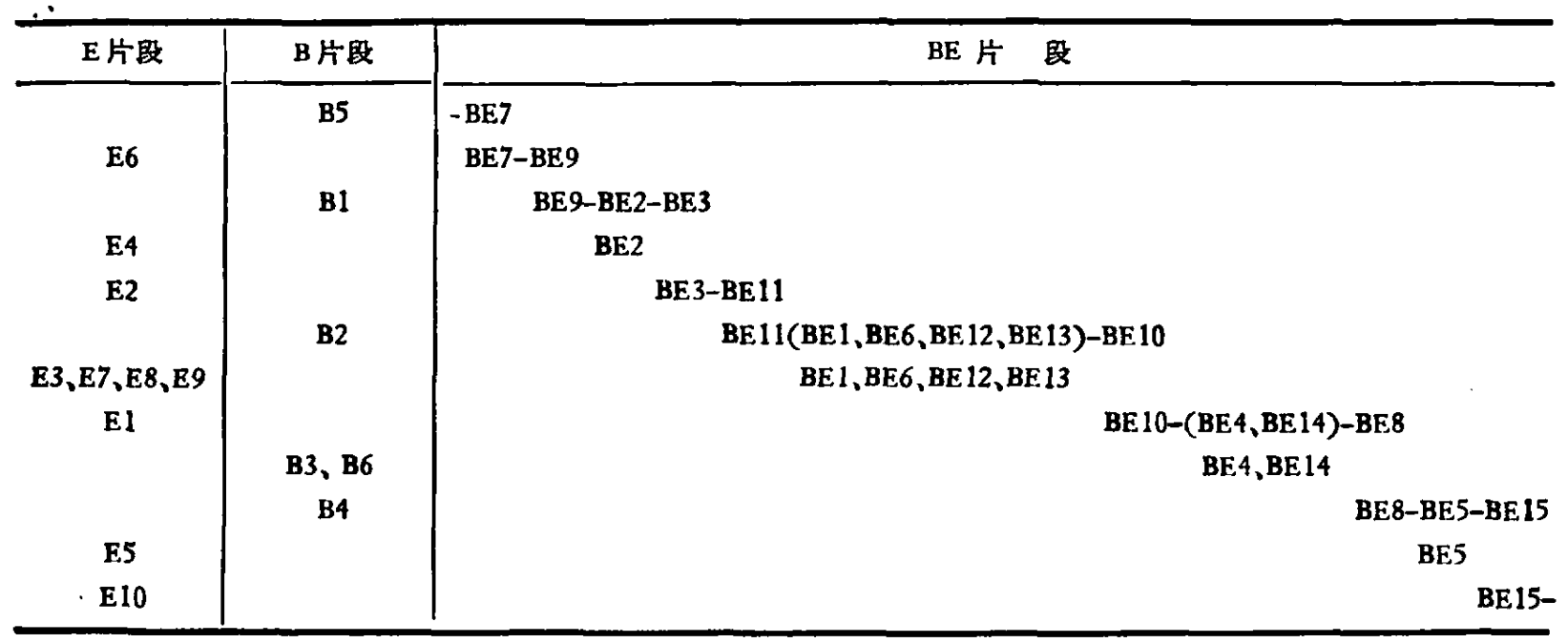

与 EcoRI-PvuII、EcoRI-SalI、EcoRI-BgIII 的限制类型相比较, 同时又将 BamHI 的限制类型 与 BamHI-PvuII、BamHI-SalI、BamHI-BglII 的限制类型相比较(图 4), 可以看出在 B3 与 E1 片段中各有一个 BgllI 切点, 在 $\mathrm{B} 1 、 \mathrm{~B} 6 、 \mathrm{E} 1$ 与 $\mathrm{E} 2$ 中各有一个 Sall 切点, 在 $\mathrm{B} 2 、 \mathrm{~B} 3 、 \mathrm{~B} 4$ 与 $\mathrm{E} 1$ 、 E3、E5 中也各有一个 PvuII 切点. 由于 E与 B 片段的位置已在 pBR322:: Tn233(CH) 中确 定, 因此被 PvuII、SalI 与 BglII作用所产生的限制片段的位置可以在图上定出. 图 5 即为本 研究中所用的七种限制性内切酶所建成的 $\mathrm{pBR} 322:: \mathrm{Tn} 233(\mathrm{CH})$ 的物理图. 由于 $\mathrm{pBR} 322$ 的 物理图已经知道 ${ }^{[3]}$, 因此 $\operatorname{Tn} 233(\mathrm{CH})$ 的所在范围即可以识别出来. 


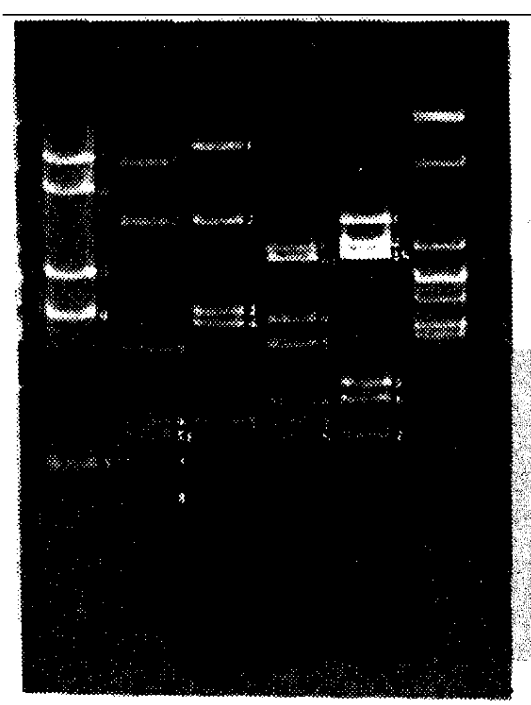

a $\quad b \quad c \quad d \quad e \quad f$

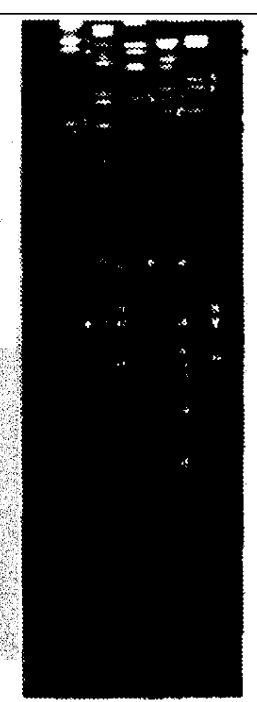

g h i j $\mathbf{k}$

图 3 pBR322:: Tn233(CH) 质粒 DNA经限制性内切酶消化后的产物

DNA 经 BamHI(a,g), BamHI-Hind III $(b, h)$, HindIII(c,i) EcoRI-Hind III(d,j), EcoRI(c,k) 完全消化后，在 $1.0 \%$ 琼脂榶（ $a 、 b 、 c 、 d 、 c 、 f ）$ 与 $5 \%$ 聚丙烯酰胺 $(g 、 h 、 i 、 j 、 k)$ 姚胶上电泳. 经 BamHI-EcoRI 消化的 $\lambda$ CI857S7 DNA(f) 作为分子年标准

表 3 各H、B 与 $\mathrm{BH}$ 片段间的相互关系

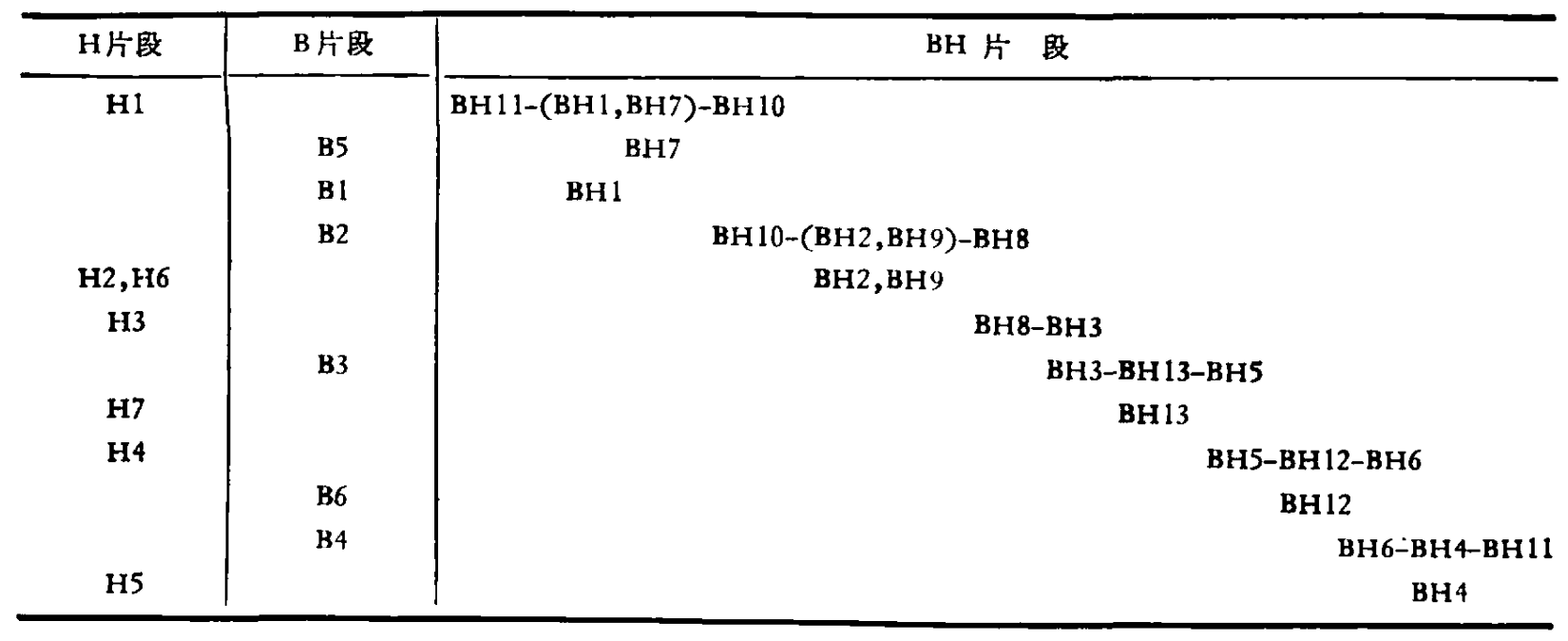

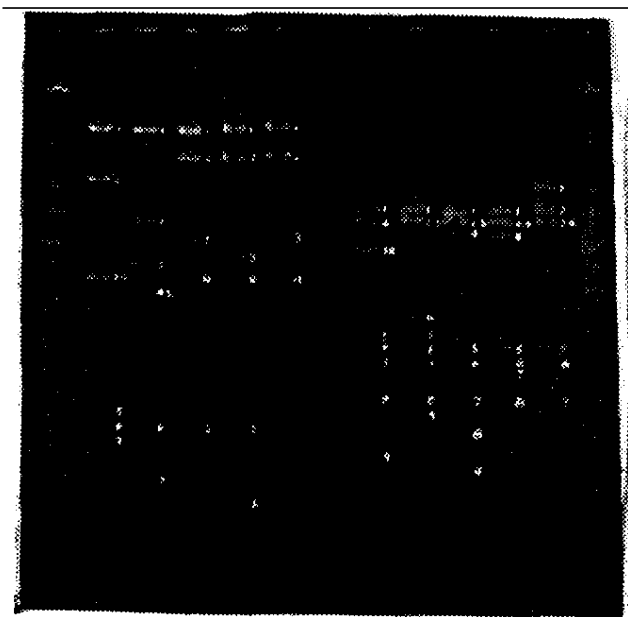

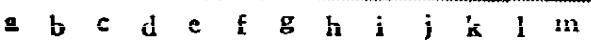

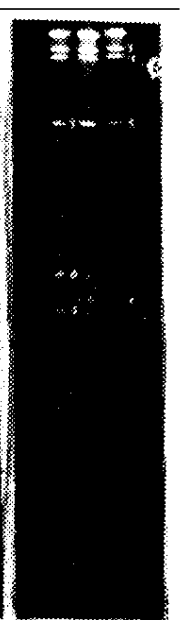

n $0 \mathrm{p}$
图 4 pBR322:: Tn233(CH) 质柆 DNA 经 限制性内切酶消化后产物的电泳

DNA 经 BamHI-Pst I(b)、BamHI-PvulI (c)、 BamHI-Sal I(d)、BamHI-BgI II(c)、BamHI (f)、EcoRI-Pst I (h), EcoRI-PvuII (i), EcoRISalI(j)、EcoRI-Bgl II(k)、EcoRI (l)、BamHISal I(n)、 $n+p(o) 、 B a m H I(p)$ 完全消化后, 在 $1.0 \%$ 琼脂糖 $(\mathrm{a} \rightarrow \mathrm{m})$ 与 $5.0 \%$ 繁丙㛓酰胺 $(\mathrm{n} \rightarrow$

p) 媬胶上进行电泳分离，经 BamHI-EcoRI 消 化后的 $\lambda \mathrm{CI} 857 \mathrm{~S} 7 \mathrm{DNA}$ 用作分子具标准

$$
\text { (a.g.m) }
$$




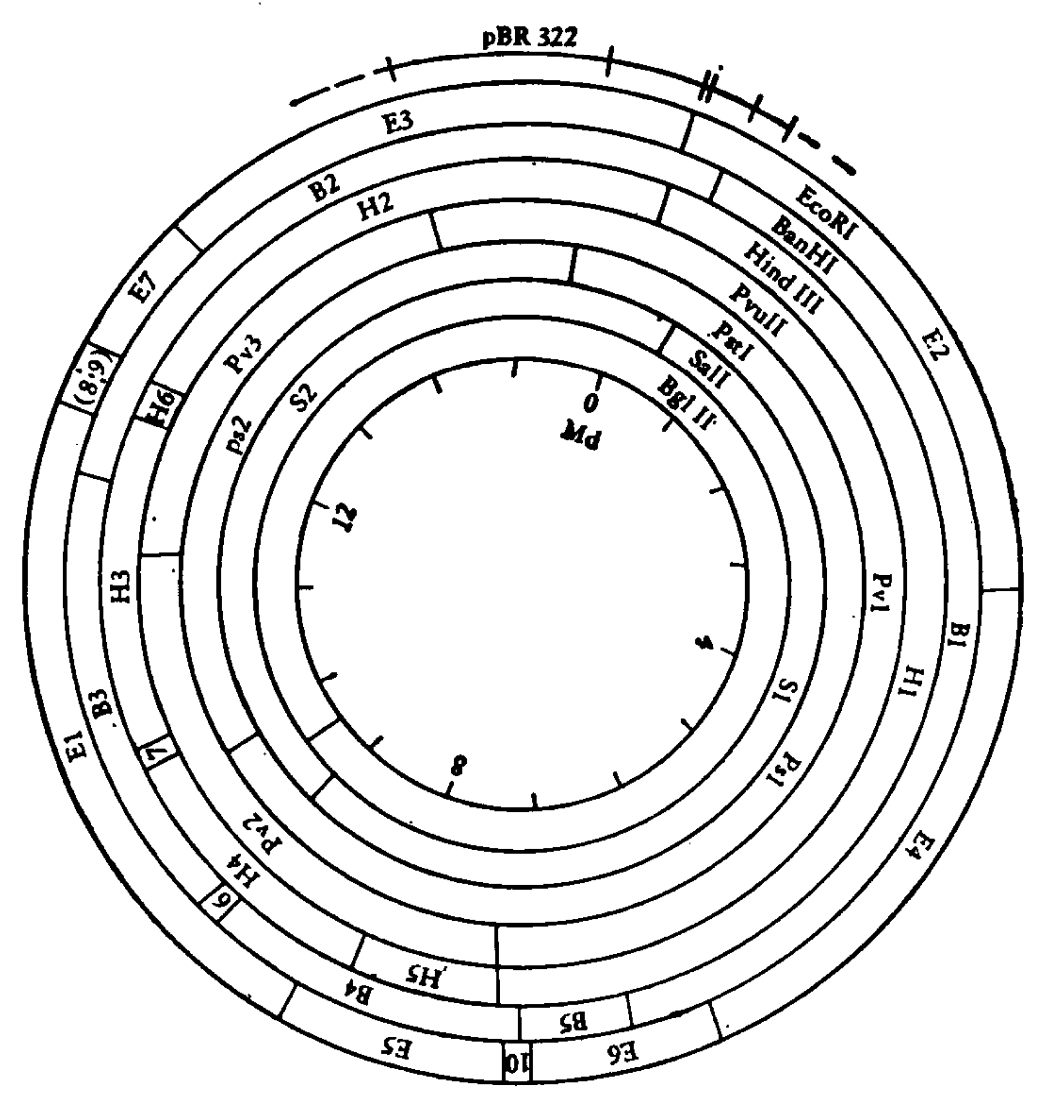

图 $5 \mathrm{pBR} 322:: \operatorname{Tn} 233(\mathrm{CH})$ 质粒 DNA 的限制图

图的上部为 $\mathrm{pBR} 322 \mathrm{DNA}$ 的所在区域,最内圈中每一小格为 $1 \mathrm{Md}$

致谢: 我们非常感谢焦瑞身教授审阅本文与汪大建博士曾给限制性内切酶. 同时还感谢中国科学院上 海生理研究所张铁和余蛡同志在电镜工作上给予大力支持.

\section{$\Rightarrow$ 文 文}

[1] 洪血民等,选传学报, 6(1979), 239.

[2] 陈剑民等,遭传学报, 8(1981), 189.

[3] Sutclitfe, J. G., Nucl. Acids Res., 5(1978), 2721. 